\title{
Introduction to Pasture-Raised Poultry: Getting Started ${ }^{1}$
}

\author{
B. Burbaugh, E. Toro, and A. Gernat ${ }^{2}$
}

\section{Introduction}

There are several important points for small and medium scale poultry producers to consider when thinking about producing pasture-raised poultry as an alternative to traditional production. This document provides information that will help identify the characteristics of alternative poultry production, explain the opportunities and challenges associated with pasture based production systems, provide an overview of breed selection for egg-type laying hens and meat-type birds, as well as discussing to the equipment and practices that facilitate getting birds off to a good start.

\section{Alternative Poultry Production}

Using the word alternative in this context is a misnomer. Many types of poultry have been raised on pasture for hundreds of years. Pastured poultry production is used to describe a variety of production systems in which birds have access to pasture on a regular basis. Production systems vary widely from stationary houses with permanent yards to portable houses that are moved frequently to a new pasture (Fanatico, 2007). Additionally, birds may be allowed to free range in the pasture (Figure 1), most commonly seen in laying flocks or be confined to a portable house that is rotated throughout the pastures (Figure 2). There are no parameters for stocking rates on pastured poultry in the U.S.

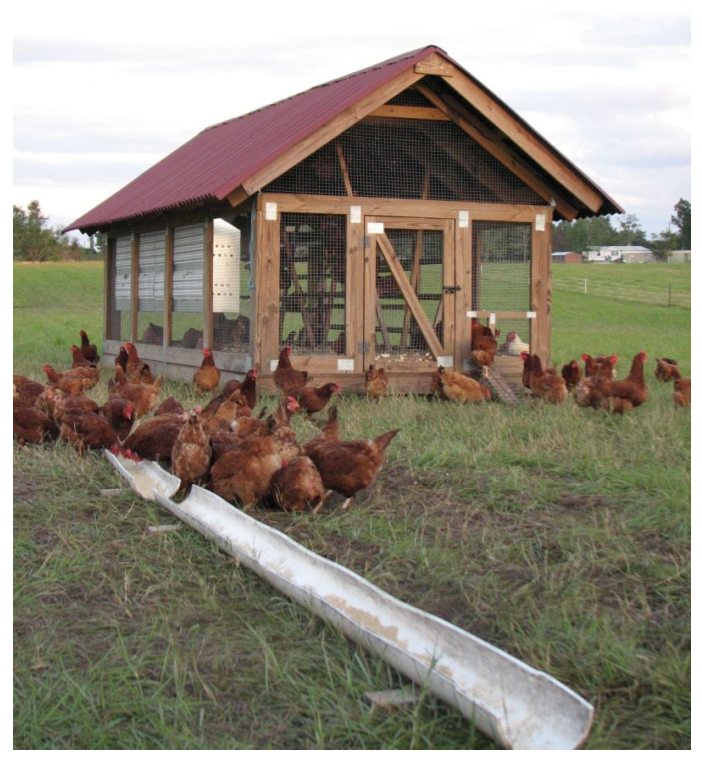

Figure 1. Free range laying flock. Photo by: Wanda Laughlin, UF/IFAS

1. This document is AN232, one of a series titled Introduction to Pasture-Raised Poultry of the Animal Sciences Department, Florida Cooperative Extension Service, Institute of Food and Agricultural Sciences, University of Florida. Original publication date January 2010. Visit the EDIS Web Site at http://edis.ifas.ufl.edu.

2. Brad Burbaugh, extension agent I, Duval County Extension; Elena Toro, extension agent I, Suwannee County Extension; and Abel Gernat, chair and professor, Zamorano, Panamerican School of Agriculture, Zamorano, Honduras; Florida Cooperative Extension Service, Institute of Food and Agricultural Sciences, University of Florida, Gainesville, FL. 32611

The Institute of Food and Agricultural Sciences (IFAS) is an Equal Opportunity Institution authorized to provide research, educational information and other services only to individuals and institutions that function with non-discrimination with respect to race, creed, color, religion, age, disability, sex, sexual orientation, marital status, national origin, political opinions or affiliations. U.S. Department of Agriculture, Cooperative Extension Service, University of Florida, IFAS, Florida A. \& M. University Cooperative Extension Program, and Boards of County Commissioners Cooperating. Larry Arrington, Dean 


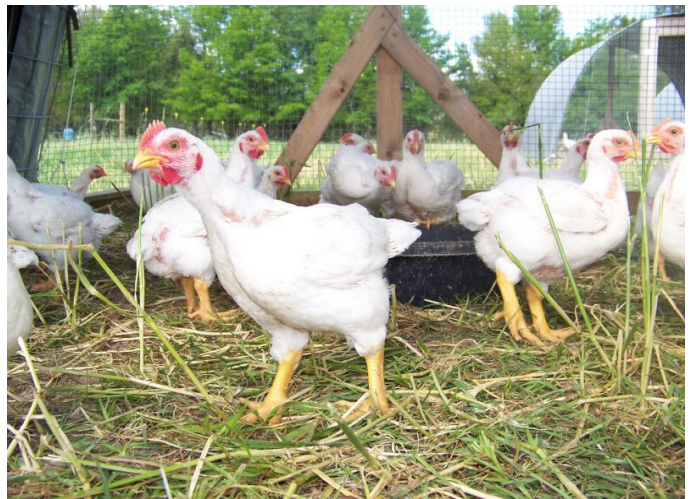

Figure 2. Cornish cross broiler inside a hoop house. Photo by: Elena Toro, UF/IFAS

\section{Organic Production}

Any number of pasture-based systems can be classified as organic if the producer chooses to follow the certification process which requires that feed, pasture and processor be certified organic. In terms of organic production, the USDA'S National Organic Program requires outdoor access and organic feeds produced without synthetic chemicals and prohibits the use of antibiotics (USDA NOP, 2006; Fanatico, 2007). In Florida, there are a number of producers that follow organic standards for raising their flock but have chosen not to become certified organic for various reasons. For more information on organic standards in Florida contact Florida Organic Growers Association (www.foginfo.org). The main drawback of organic production is the elevated cost of feed and the lack of processing facilities that offer services for certified organic producers.

\section{Opportunities of Pastured Poultry Production}

According to the National Center for Appropriate Technology (NCAT), there is a strong demand for pasture-raised poultry products when marketed directly to consumers. These types of operations can be managed by one person and producers can start small and grow as they become proficient in producing and marketing poultry and/or eggs. There is minimal initial capital investment compared to most agricultural enterprises. However, poultry products can also attract customers for other products. Moreover, pastured poultry production is arguably a more sustainable system because the nutrients in poultry excreta are being deposited into the soil. These deposits serve as a source of organic matter and nutrients that help build soil fertility, assist water retention and increase forage production. This can be especially beneficial in areas with deep sandy soils and low fertility.

\section{Challenges of Pastured Poultry Production}

The challenges associated with pasture-raised poultry are labor, seasonality and processing. This is a labor intensive operation: the birds will need to be fed, watered and moved at least once--and sometimes twice--daily. Meat production in North Florida is mostly seasonal with production and harvest ranging from February to June and August to December in order to avoid extremes in temperature. The climactic conditions will dictate how early or late in the season birds can stay in the pasture because weather related stress can affect feed conversion and meat quality. On the other hand, laying flocks can cope with varying climactic conditions if adequate housing is provided. Predation pressure also presents challenges, especially for new producers because it takes time to develop predator control strategies to minimize losses.

The biggest challenge is finding processing facilities that will kill and process birds for small producers. The Florida Department of Agriculture and Consumer Services/Division of Food Safety is responsible for regulating poultry processing when 20,000 birds or less are processed per calendar year by an individual. To learn more about the regulations that must be followed to process dressed poultry visit UF/IFAS Pastured-Poultry Virtual Field day at http://vfd.ifas.ufl.edu/pastured_poultry/or contact the Florida Department of Agriculture/Division of Food Safety. Exemptions from inspection requirements of the Poultry Products Inspection Act provided by the USDA for small scale poultry slaughter and processing are not valid in Florida. All labels for poultry products should follow guidelines established by the US Food and Drug Administration (FDA) Food Labeling Guide. For more information visit: http://www.fda.gov/Food/

GuidanceComplianceRegulatoryInformation/ GuidanceDocuments/FoodLabelingNutrition/ FoodLabelingGuide/default.htm 


\section{Meat Birds: Breed Selection}

Unlike with laying hens there are limited breed options for meat birds. The options include the Cornish cross hybrids which are selected for commercial production systems. Cornish crosses are considered a fast-growing broiler. These broilers reach a market weight of five to six pounds in approximately seven to eight weeks. Due to the fact that Cornish cross broilers are harvested at a younger age their meat tends to be more tender and juicy and does not exhibit a strong flavor like heritage birds (Chambers et al. 1989).

An emerging trend in pastured poultry production is the use of dual purpose heritage breeds to help preserve the genetic pool of poultry in the United States. Heritage breeds are breeds recognized by the American Poultry Association prior to the mid $20^{\text {th }}$ century. Heritage breeds include barred silvers and dual purpose breeds like New Hampshire, Buff Orpington (Figure 3) and Barred Rocks (Figure 4). With dual purpose poultry breeds males are selected for meat production and females for egg production. The dual purpose chicken will not provide a large carcass as a meat bird, nor lay as many eggs as an egg layer (ALBC, 2009). These birds tend to grow slowly, eat more feed and may take up to 12 weeks to reach market weight. Heritage breeds are also considered to have a stronger flavor because the age at which the birds are killed and processed is an important factor that contributes to flavor (Le Bihan-Duval, 2003; Fanatico, 2007). For more information on raising heritage chickens refer to http://www.albc-usa.org

Breed selection will be based on your preferences and in some instances the preferences of your market and consumer demand.

\section{Selecting Laying Hens}

Commercial hatcheries offer a wide variety of options when it comes to laying hens. A common misconception is that hybrids are man-made breeds. In reality hybrids are a cross between known breeds whose offspring will usually grow faster, provide flock uniformity and increased egg production. This is often referred to as hybrid vigor. Some examples of hybrids include red sex links, production reds and

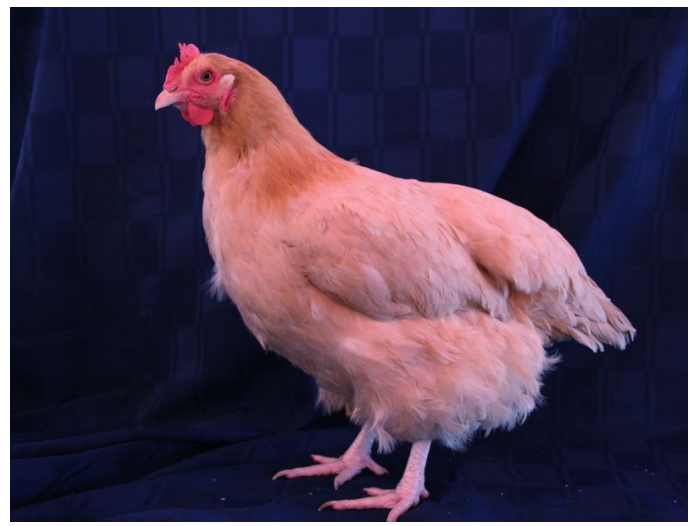

Figure 3. Buff Orpington hen. Photo by: Tom Wright, UF/IFAS

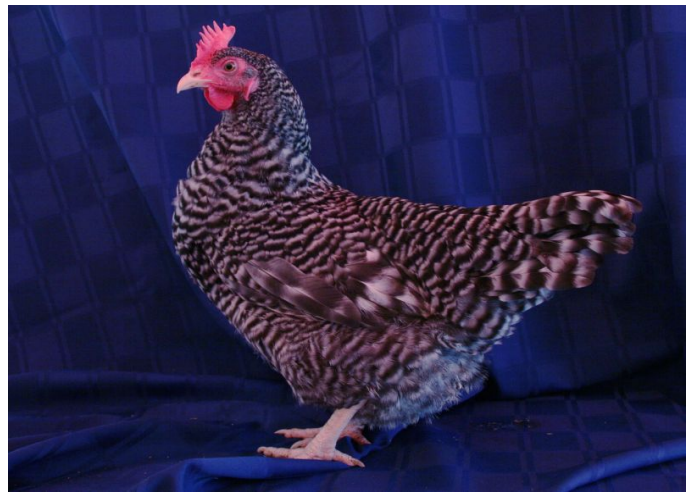

Figure 4. Barred rock hen. Photo by Tom Wright, UF/IFAS

white leghorns. Once again, personal preference and market will drive the breed selection process.

Heritage breeds are also an option in a layer operation. A benefit of using heritage breeds is the conservation of genetic diversity. Some of the breeds in this category include New Hampshire, Rhode Island Red (Figure 5), Buff Orpington, Minorca and Ancona. Additionally, heritage breeds have adapted to changing environmental conditions and are natural and efficient foragers. Using this type of bird in a pasture-based production system can also be used as a marketing tool.

Some producers prefer to select a breed based on the color of eggs desired. A rule of thumb for brown and white egg layers is the color of the bird's ear lobes will, in many cases, correspond to the color of the eggs which they will lay. White Leghorns are among the most popular and productive layers of white eggs whereas Rhode Island Reds are the second most popular and produce large brown eggs. If more unique shell color or "designer eggs" are desired then the Araucana and Ameracana breeds will provide 


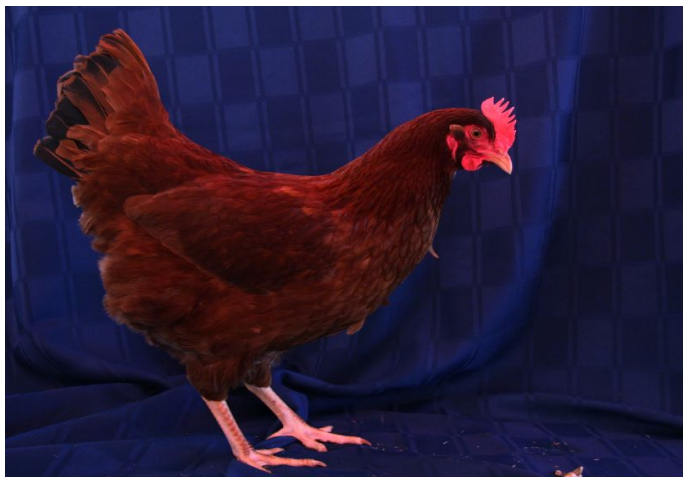

Figure 5. Rhode Island Red hen. Photo by Tom Wright, UF/IFAS

these results. For more information, characteristics of representative breeds of chickens can be found in Table 1.

\section{Starting the Birds}

In a pasture-based poultry system newly hatched chicks will not go directly into the pasture. During the first couple of weeks an enclosed structure is needed in order to provide temperature regulation, feed and water. This enclosed structure is more commonly known as a brooder. In the case of broilers, the chicks will remain in the brooder for approximately three weeks or until they are sufficiently feathered to withstand climactic conditions. In contrast, chicks that will later become layers will need to remain in the brooder for approximately six weeks. These first couple of weeks will determine the long term survival, development and health of the flock in the pasture.

The brooder should meet the following requirements:

- One-half of a square foot per bird.

- A heat source (infra red lamps are recommended, have two in case one burns out).

- Three inches of dry bedding such as wood shavings, hay or straw. Try to avoid slippery surfaces like newspaper.

- One quart of water for every 25 birds.

- Clean feeders. The feeder should be placed near the heat source, but not directly underneath it.
- Some form of ventilation. Chicks need draft protection, but proper ventilation during the brooding period is very important (DeCubellis, 2007).

During the first week, the temperature in the brooder should remain a constant 95 degrees Fahrenheit. After the first week the temperature should be lowered five degrees per week for the next two to three weeks, after the third week the birds are typically ready to be moved into the pasture. The temperature in the brooder can be decreased by raising the heat source. It is very important that fresh water and feed be offered ad libitum (free choice) daily because it is vital for their growth and health once they are in the pastures. Care should be taken to insure that the feed and water are not allowed to become too warm because this will result in the chicks not eating and drinking as much as they need.

On delivery day, you need to have the brooder up and running 24 hours before the chicks arrive in order to detect any problems beforehand. Also make sure that the hatchery sends the chicks via overnight mail to avoid losses and to get the chicks to starting drinking and eating feed (Figure 6). When placing the birds in the brooder each bird should be introduced to the water source by dipping their beak directly into the water.

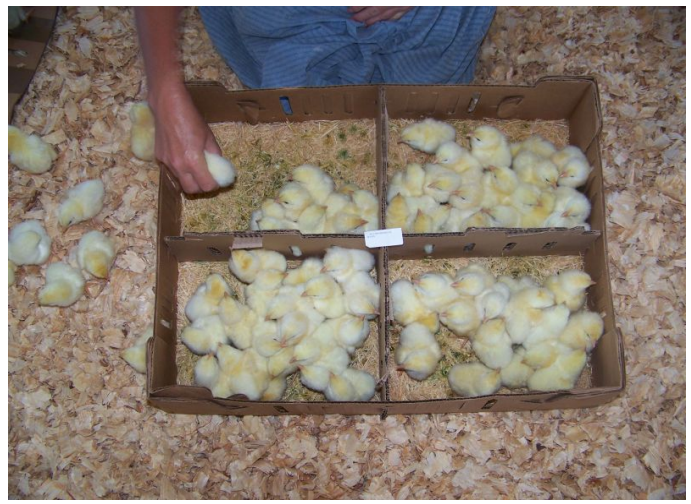

Figure 6. Baby chicks on delivery day. Photo by: Elena Toro, UF/IFAS

\section{Conclusion}

U.S. consumers are increasingly interested in products they perceive as naturally-produced or environmentally-friendly, that provide a high level of nutrition, good flavor, improved welfare for the birds, 
and provide information about how the food was produced. These interests have led to specialty markets for poultry produced in alternative systems such as free-range or organic (Fanatico, 2007). In Florida, the producers of pastured poultry can meet the demands of this growing segment of consumers. However, the lack of processing facilities is the main challenge that producers will need to overcome either by building their own facilities, retrofitting existing ones or working collaboratively to gain access to mobile processing units.

\section{Further Information}

For production system examples, educational videos, and science-based presentations online visit the pastured poultry virtual field day at http://vfd.ifas.ufl.edu/pastured_poultry.

\section{Bibliography}

merican Livestock Breeds Conservancy. (1993-2009, ). Definition of Heritage Chicken. Retrieved October 10, 2009, from American Livestock Breeds Conservancy: http://www.albc-usa.org/heritagechicken/ definition.html

Chambers, J. R. (1989). Comparison of sensory properties of meat from broilers of modern stocks and experimental strains differing in growth and fatness. Canadian Institute of Science and Technology Journal , 353-358.

DeCubellis, C. (2007, July). Care of Baby Chicks. Retrieved October 10, 2009, from EDIS: http://edis.ifas.ufl.edu/AN182

Fanatico, A. (2007, May). SPECIALTY POULTRY PRODUCTION: Impact of Alternative Genotype, Production System, and Nutrition on Performance, Meat Quality and Sensory Attributes of Meat Chickens for Free Range and Organic Markets. Dissertation . Arkansas, U.S.: Univesrity of Arkansas.

Fanatico, A., \& David, R. (2002, October).

Growing Your Range Poultry Business: An Entrepreneur's Toolbox. Retrieved August 10, 2009, from NCAT:

http://attra.ncat.org/attra-pub/PDF/poultrytoolbox.pdf
FDA U.S. Food and Drug Administration. (2009, May 8). Guidance for Industry A Food Labeling Guide. Retrieved June 3, 2009, from Food Labeling Guide:

http://www.fda.gov/Food/

GuidanceComplianceRegulatoryInformation/

GuidanceDocuments/FoodLabelingNutrition/

FoodLabelingGuide/default.htm

Le Bihan-Duval, E. (2003). Genetic Variability of Poultry Meat. Proceedings of the 52nd Annual National Breeders Roundtable, (pp. 11-20). Saint Louis, MO.

Neisham, M.C., Austic, R.E. and Card, L.E. (1979). "Poultry Production" 12th Edition. Lea and Febiger. Philadelphia, USA. 
Table 1. Characteristics of some representative breeds of chickens.

\begin{tabular}{|c|c|c|c|c|c|c|c|c|}
\hline \multirow[t]{3}{*}{ BREED } & \multicolumn{2}{|c|}{ Standard } & $\begin{array}{c}\text { Type of } \\
\text { comb }\end{array}$ & $\begin{array}{l}\text { Color of } \\
\text { Earlobe }\end{array}$ & $\begin{array}{c}\text { Color of } \\
\text { Skin }\end{array}$ & $\begin{array}{c}\text { Color of } \\
\text { Shank }\end{array}$ & $\begin{array}{l}\text { Shanks } \\
\text { feathered? }\end{array}$ & $\begin{array}{c}\text { Color of } \\
\text { Egg }\end{array}$ \\
\hline & \multicolumn{2}{|c|}{ Weight (lbs) } & & & & & & \\
\hline & Cock & Hen & & & & & & \\
\hline \multicolumn{9}{|l|}{ American Breeds } \\
\hline Plymouth Rock & $91 / 2$ & $71 / 2$ & Single & Red & Yellow & Yellow & No & Brown \\
\hline Wyandotte & $81 / 2$ & $61 / 2$ & Rose & Red & Yellow & Yellow & No & Brown \\
\hline Rhode Island Red & $81 / 2$ & $61 / 2$ & $\begin{array}{l}\text { Single } \\
\text { and rose }\end{array}$ & Red & Yellow & Yellow & No & Brown \\
\hline Jersey Black Giant & 13 & 10 & Single & Red & Yellow & Black & No & Brown \\
\hline New Hampshire & $81 / 2$ & $61 / 2$ & Single & Red & Yellow & Yellow & No & Brown \\
\hline \multicolumn{9}{|l|}{ Asiatic Breeds } \\
\hline $\begin{array}{l}\text { Brahma } \\
\text { (light) }\end{array}$ & 12 & $91 / 2$ & Pea & Red & Yellow & Yellow & Yes & Brown \\
\hline Cochin & 10 & $81 / 2$ & Single & Red & Yellow & Yellow & Yes & Brown \\
\hline $\begin{array}{l}\text { Langshan } \\
\text { (black) }\end{array}$ & $91 / 2$ & $71 / 2$ & Single & Red & White & $\begin{array}{l}\text { Bluish- } \\
\text { black }\end{array}$ & Yes & Brown \\
\hline \multicolumn{9}{|l|}{ English Breeds } \\
\hline Australorp & $81 / 2$ & $61 / 2$ & Single & Red & White & Dark Slate & No & Brown \\
\hline Cornish (dark) & 10 & $71 / 2$ & Pea & Red & Yellow & Yellow & No & Brown \\
\hline $\begin{array}{l}\text { Dorking } \\
\text { (Silver-gray) }\end{array}$ & 9 & 7 & Single & Red & White & White & No & White \\
\hline $\begin{array}{l}\text { Orpington (buff and } \\
\text { white) }\end{array}$ & 10 & 8 & Single & Red & White & White & No & Brown \\
\hline Sussex & 9 & 7 & Single & Red & White & White & No & Brown \\
\hline \multicolumn{9}{|l|}{$\begin{array}{l}\text { Mediterranean } \\
\text { Breeds }\end{array}$} \\
\hline Leghorn & 6 & $41 / 2$ & $\begin{array}{l}\text { Single } \\
\text { and rose }\end{array}$ & White & Yellow & Yellow & No & White \\
\hline $\begin{array}{l}\text { Minorca } \\
\text { (S.C. black) }\end{array}$ & 9 & $71 / 2$ & Single & White & White & White & No & White \\
\hline Ancona & 6 & $41 / 2$ & $\begin{array}{l}\text { Single } \\
\text { and rose }\end{array}$ & White & Yellow & Yellow & No & White \\
\hline Andalusian (blue) & 7 & $51 / 2$ & Single & White & White & White & No & White \\
\hline
\end{tabular}

